\title{
Outsourcing: A Potential Shock Absorber for the Hotels in Bono and Ahafo Regions
}

\author{
Noble Amoako Sarkodie ${ }^{1}$ and Serwaa Ntim Olivia ${ }^{2}$ \\ Sunyani Technical University, Ghana \\ Department of Hospitality and Tourism \\ ${ }^{1}$ Corespondence: noblesark@yahoo.com.Tel \#: +233-249169578
}

\begin{abstract}
This study assesses the effect of outsourcing on organisational performance of hotels in Bono and Ahafo Regions. The study adopted quantitative method using descriptive survey. Forty (40) managerial staffs were purposively and randomly sampled. The primary data was gathered using questionnaire while secondary data were obtained from the list of registered hotels from Ghana Tourism Authority and validated through peer review. Descriptive and inferential statistics were used to analyses the data gathered. The study found that outsourcing had contributed to increase productivity, profits, encourages employee innovation, maintains competitiveness in the market, allows hotel to focus on core areas and provides faster and quality service to customers. However, the study revealed some challenges that hotels operators face as a result of outsourcing some of their operations such as exposure of itself to operational risks; it affects the continuity of skill supply and the retention of in-house knowledge and expertise, and it causes disruption to the continuity of the services. It is recommended that, hotels should put in place risk control measures so that failures on the part of the outsourced agencies are curtailed.
\end{abstract}

Keywords: Outsourcing, absorber, hotels, Bono Region, Ahafo Region.

Citation: Sarkodie, N. A. and Ntim, S. Outsourcing: A Potential Shock Absorber for the Hotels in Bono and Ahafo Regions, 2020; 5(3): 96-106.

Received: May 20, 2020

Accepted: September 30, 2020 


\subsection{Introduction}

In recent times outsourcing has been implemented in many hospitality industries owing to many opportunities that it provides such as improving productivity, flexibility, speed, skills, innovation, cost savings, reduction in overhead costs, access to new technologies and minimized risks (Leavy, 2014, Olive, 2016, Elmuti and Kathawala, 2018, Bolat and Yilmaz,2018). In view of that, outsourcing is now considered the best management strategy by vast majority of hospitality industries and it is no longer sensible for organisations to stick to the traditional forms of expansion that is, recruiting of more employees and building more facilities when they can simply contract services to another organisation at a cheaper cost..

Despite opportunities in outsourcing, there are still challenges with outsourcing. These includes: failure to attain the expected cost saving, loss of jobs and talented workers Okeke-Ezeanyanwu(2017) further, argued that outsourcing may reduce organizational innovation, may switch knowledge to the outside service provider and may reduce control over organization's functions and may lead to delay in communications and project implementation. Nonetheless, there is limited literature on the impact of outsourcing in hotels in Bono and Ahafo Region in Ghana. This study therefore seeks to determine the influence of outsourcing within one to three- star hotels in the Region.

In Ghana, the tourism and hospitality sector has emerged as an important earner of foreign exchange ranking third after gold and cocoa and is currently contributing 6.2\% to Ghana's Gross Domestic Product (GTA, 2018). The industry also employed about 487,000 people in 2017 (GTA, 2018). These figures clearly indicate that the role of tourism and hospitality as a job provider is significant and seen as a major potential engine of growth and development.

However, due to uncertainties such as corona virus pandemic which has caused significant disruption to every aspect of hotel business and forced managers to make major changes in order to adapt to the evolving situations in the industry, this projected level of targeted employment may or may not be achieved if hospitality industry would have to perform all of its core businesses without outsourcing. It is in line with this that, the researchers seek to find out whether outsourcing would be a potential shock absorber for hospitality industry to be adopted to fill the gap that has been created in general and Bono Ahafo Region in particular

\subsection{Objectives of the Study}

The general aim of this study is to examine the effect of outsourcing on hotels performance in Bono Ahafo Region. Specifically, the study seeks;

1. to assess the effect of outsourcing on hotels performance.

2. to identify challenges hotels face for adopting outsourcing.

3. suggest possible solutions to challenges associated with outsourcing.

\subsection{Significance of the study}

1. It is hoped that the findings of this study will provide information on outsourcing practices in hospitality industry in Ghana.

2. The finding of the study is relevant to management as it enabled the management of hotels to know the influence that outsourcing have on the overall hotel performance.

3. The findings of the study is hoped to unravel the effect of outsourcing on hotels performance in the prevailing competitive environment.

4. The study facilitates individual researchers to identify gaps in the current study and carry out research in those areas. 


\subsection{Literature Review}

\subsection{Definitions of Outsourcing}

Outsourcing is a management strategy by which organisations assign an experienced and efficient service provider to perform their non-core functions, by doing so they can save time and money (Stroh and Treehuboff, 2012). In other words, it is a technique of acquiring goods and services by contract from an external supplier. Outsourcing is also the process of contracting an outside company to provide a service previously performed by staff. In many cases, outsourcing involves a transfer of management responsibility for delivery of service and internal staffing patterns to an outside organization. Subcontracting, contracting out, staff augmentation, flexible staffing, employee leasing, professional services, contract programming, consulting, and contract services are all terms which refer to outsourcing (Dibbem \&Bustinza, 2016). According to (Letica, 2016) outsourcing is a strategy by which an organisation pact out some of their main services to specialize and efficient service providers, who turn into valued business partners. Isaksson and Lantz, (2015) further, defined outsourcing as a decision by organisations to have an external supplier to perform a function that would have otherwise been performed internally by organisation staff.

\subsection{Effects of Outsourcing on hotels Performance}

Muweesi, (2011) set out to gain greater insights into the impact of outsourcing on organisational performance in private hotels in Uganda. The study used quantitative method. Purposive and simple random was used to select respondents. The findings disclosed that outsourcing of hotel industry positively contributed to cost efficiency. The study recommended hotel industry to outsource more in order to benefit more on cost efficiency.

In a related study, Akinbola(2012) investigated the effects of outsourcing strategies on the organisational performance of fast foods industry in Lagos. Questionnaires were the medium through which the primary data were collected and 300 questionnaires were administered to 10 chosen fast food organisation to answer the research questions and hypotheses. The study found that outsourcing has positively affected the performance of fast food industry and the findings established that the hospitality industry has benefited from outsourcing its business process to reduce cost of operation. The study also found that outsourcing improves customers' relationship. The study recommended that fast food companies should maintain business relationships that would help in transacting negotiation with outsourcing vendors to boost the profitability of organisations.

Suraju and Hamed (2013) also, conducted a study to examine outsourcing services as a strategic tool for organisational performance in the Nigerian food, beverage, and tobacco industry. Naïve estimator and weighted estimator were used to analysis the data. Cross sectional survey and questionnaire were administered to the respondents. The study found out that the more an organisation outsourced, the higher its organizational growth. Also, organisational productivity is positively correlated to the amelioration of competitive advantage of labor productivity and average production cost. The study also revealed that outsourcing is beneficial to organizational performance and enhances firm's financial economies and competitive advantage in the market place.

Yeboah (2013) carried out a study to examine the relationship between outsourcing and organisational performance in the services sector using SPSS to correlate the variables. Questionnaire was used to solicit data from a population of 50 firms operating in the banking and insurance sectors of the economy of Ghana. The study found that, there is no statistically significant correlation between outsourcing and organizational productivity. The study further, found that there is statistically significant correlation between outsourcing and quality. Finally, the study revealed that, there is statistically significant correlation between outsourcing and competitive advantage.

In furtherance, Kiptum (2014) set out to carry out a study on the influence of outsourcing on the performance of three to five star hotels in Nairobi County. A descriptive research design was used and the target population was all the three to five star hotels in Nairobi County. The main instrument was structured questionnaire having both 
open ended and closed ended questions. The data obtained was analysed using statistical package for social sciences. The study found out that outsourcing has an influence on increased customer satisfaction, capacity of innovation and flexibility, reduced cost and improved quality of service; organizational competiveness and increased sales turnover and profitability.

In a similar study, Agyemang, Aikins, Asibey and Broni, (2014) sought to investigate the strategies in the outsourcing process, the challenges associated with outsourcing in the hotel industry and what benefits are derived from outsourcing of non-core functions. Primary data was obtained through questionnaire and personal observation of Anita hotel, Noda hotel and Golden Gate hotels in Kumasi. Purposive sampling was used to select fifty (50) respondents comprising core management staff and other key heads of the departments and the main crew. The outcome of the study revealed that hotels have been focusing on their core functions in the areas of accommodation, food and bar services and housekeeping and have outsourced most of their non-core functions.

Additionally, Letica (2016) studied about the impact of outsourcing on organisational performance in Century Bottling Company Limited. The study unraveled that organisations outsource to get special expertise, speed up delivery of services, decrease cost and get enough time to concentrate on their core activities. The study recommended that organisations should outsource some of their services so as to reduce costs and focus on core activities.

\subsection{Challenges of Outsourcing}

Like any restructuring exercise and management decision making in business, there are risks associated with outsourcing, managers need to consider carefully (Lau and Zhang, 2013) and these may be; the possibility of over dependence on by suppliers which make switching costs to other suppliers in future prohibitively expensive. Eyaa (2010) asserts that, high prices being imposed on suppliers due to increasing trends in outsourcing, the demand for suppliers is so high and has pushed the rates being charged by the suppliers to be high. According to Barthelemy(2010), there is a possibility that vital organisation information may be at a risk of being linked to the organization's competitors which is dangerous since some suppliers may be spies to the organisation.

Lichtenthaler (2011) found out that it is increasingly becoming a critical part of strategic management to outsource innovation and new product development. However, there is still a grey area, with a lot of heated debate on whether outsourcing may expose the organisation to business risk..Cox (2014) further, outlines some common outsourcing mistakes, which include failure to understand pre- and post-contractual power and leverage and its relationship to moral hazard and lock-in..

In furtherance, Hiamey (2012) sought to find out from hotel managers in the Accra Metropolis of Ghana some of the challenges they face with outsourcing from a transaction cost perspective. Eight managers were interviewed from six hotels that practices outsourcing. After capturing and transcribing data, a three-tier coding system was employed to group responses under thematic networks. The global themes that emerged within and across cases were inductively analysed. The study found challenges such as poor quality of outsourced staff, lack of product knowledge by hoteliers, monopolistic tendencies by outsourcers, lack of commitment on the part of outsourced staff and cost involved in outsourcing.

\subsection{Methodology}

\subsection{Research Design}

Descriptive survey was used to execute the study. This was because the respondents were at their work places and it was very easy to reach them. The approach is justified by the fact that it captured the current perception of the population with regards to the variables of the study. 


\subsection{Study Population}

The population composed of managers working within one to three- star hotels in the Bono Ahafo Region. Managers were chosen on the grounds that they have special knowledge that was relevant to the study topic and could answer the questions very proficiently.

\subsection{Sample and Sampling Technique}

In this study both non- probability and probability techniques were employed in the selection of the respondents. Respondents were first purposively chosen and randomly selected because they were many. Consequently, forty (40) respondents were picked through lottery method, where names of the elements were balloted. This approach was possible since the researchers have a complete list of the target population of all the 231 licensed formal accommodation establishments categorised into star-rated, guests' houses and budget hotels with their names, addresses and telephone numbers of each establishment were obtained from hotel directory (GTA, 2017).

\subsection{Research Instrument}

Closed - ended questionnaire was used to gather data from the respondents in the study and was designed based mainly on a five- point Likert scales ranging from 'extremely important' to 'extremely unimportant'. The researchers employed closed ended questions since it did not require too much critical thinking to select the right responses and also has the advantage of quick and easy completion by respondents and easier to analyse. Finally, self-administered questionnaires were delivered to the selected respondents at their various work places to be filled by themselves at their own free period.

\subsection{Validity}

The questionnaires were given to colleague lecturers who are well versed in the field of study to review and comment on it. Feedback was given on each of the items; this led to the revision and modification of the questionnaires thereby enhancing the overall validity of this study.

\subsection{Data Analysis}

Frequency distribution was used to analyse background characteristics of the respondents' gender, educational level, age range and number of years of working in the hotel whilst descriptive statistics of mean and standard deviations were used for the analysis to provide data on effects and challenges of outsourcing on hotels performance in Bono Ahafo Region. Simple regression was further used to find the extent of impact of outsourcing on hotels performance in Bono Ahafo Region.

\subsection{Results and Discussions}

\subsection{Background Information of Respondents}

Table 1: Socio-Demographic Characteristics of Respondents

\begin{tabular}{lcc}
\hline Variables & Frequency & Percentage \\
\hline Gender & 26 & 65 \\
Male & 14 & 35 \\
Female & & \\
Educational level & 10 & 25 \\
SHS & 18 & 45 \\
Diploma/ HND & 10 & 25 \\
Degree & 2 & 5 \\
Masters & & \\
Age range (Years) & &
\end{tabular}


Less than 1 years

1-2 years

$\begin{array}{ll}4 & 10\end{array}$

3-5 years

$\begin{array}{ll}7 & 18\end{array}$

6-10 years

From Table 1, majority (65\%) of the respondents were males while $35 \%$ were females. This finding is contrary to the finding of (Kattara, 2015)who found $70 \%$ of females in his study and stated that females tend to be more attractive to guests, better at handling guests and more accepted than their male counterparts in people-oriented positions such as reception and marketing departments of hotels. In terms of educational attainment of respondents, 45\% had attained HND/Diploma education, 25\% each had attained degree and SHS while only 5\% had Masters' degree. What this implies is that the selected hotels managers have a lot of high quality staff. For the age group, $35 \%$ of the employees were between $18-29$ years, $62 \%$ of them were aged between $30-39$ years, and only 3\% were aged between $40-49$ years. The information above is a positive one since hotel business stands in a competitive and fast changing environment; young employees from 30-39 years are to a large extent recruited to work in the industry. The young employees are able to adjust to new environment quickly and easily especially in this technological era of business. In that respect it is ideal that the Human Resource department considers the age groups when conducting training. Further, 37\% of the respondents have worked for 6-10 years, 35\%have worked for 3-5 years, $18 \%$ have worked for $1-2$ years and 10\% have worked for less than 1 year. This implies that majority of the respondents have worked for the hotels for a year or more and therefore stand a good chance of giving reliable information regarding outsourcing.

Table 2: Effects of Outsourcing on Hotels Performance

\begin{tabular}{lcc}
\multicolumn{1}{c}{ Effects of Outsourcing on Hotels Performance } & Mean & Std. Dev. \\
\hline It leads to higher operational cost & 2.37 & 1.28 \\
Outsourcing encourages employee innovation & 3.67 & 0.56 \\
Outsourcing has helped to increase productivity & 3.70 & 0.67 \\
Outsourcing maintains competitiveness in the market & 3.46 & 0.74 \\
Outsourcing allows hotel to focus on core areas & 3.55 & 0.70 \\
It provides faster and offer better service to customers & 3.40 & 0.82 \\
Outsourcing comes with improved reliability & 3.12 & 1.00 \\
Average mean & 3.32 & \\
\hline
\end{tabular}

Source: (Field Survey, 2020)

Scale: 1.0-2.4=Disagree, 2.5-3.9=Agree

The value of average mean (3.32) indicates that outsourcing has significant effect on organisational performance. Majority of the respondents agreed $(\mathrm{M}=3.70)$ that outsourcing has helped to increase productivity. The outcome of the study implies that outsourcing non-core functions improve performance of the organisation. The study finding is supported by Alexander and Young (2016) and Okeke-Ezeanyanwu, (2017) study that found that outsourcing increase productivity. The respondents were further in agreement that outsourcing encourages employee innovation with a mean score of $(\mathrm{M}=3.67)$. The study finding implies that when management outsourced it may give a new way of thinking and totally new direction. The study finding is in line with Kiptum (2014) studies that found that, in order to survive and compete in the constantly changing business environment, organisations must partner with other organisations that have the capacity to innovate quickly and continuously. 
Again, respondents agreed $(M=3.55)$ that outsourcing allows hotel to focus on core areas. Implying that hospitality operators could concentrate on their core areas, to provide accommodation and quality food and beverage service. The results corroborate the outcome of the study conducted by Elmuti(2014) and Agyeman et al. (2014) that found out that outsourcing enabled the organisation to focus on their core businesses. Furthermore, respondents agreed $(M=3.46)$ that outsourcing maintains competitiveness in the market. It implies that hospitality industry could deliver much better services as a result of outsourcing. The findings of the study support the studies of Suraju and Hamed (2013) who noted that, outsourcing can increase competitive advantage in marketing.

In furtherance, respondents agreed $(\mathrm{M}=3.40)$ that outsourcing provides faster and offer better service to customers. The finding of the study, gives credence to the fact that, the extra hands that will be made available as a result of outsourcing could be redeployed to other department to help increase efficiency. The study outcome is in line with the study of Kiptum (2014) that found that a well-managed outsourcing can lead to efficient and better service to customers.

Other effects were indicated as higher operational and outsourcing comes with improved reliability with a mean score of $(\mathrm{M}=3.12)$ and $(\mathrm{M}=3.67)$ respectively. This means that, customers' expectations are met when organisations outsourced.

\subsection{Outsourcing Challenges}

The respondents were asked to indicate the challenges encountered as a result of adopting outsourcing. The results are shown in Table 3.

Table 3: Challenges Managers encountered in Adopting Outsourcing

\begin{tabular}{lcc}
\hline \multicolumn{1}{c}{ Challenges Managers encountered in Adopting Outsourcing } & Mean & Std. Dev. \\
\hline Decrease in customer satisfaction & 2.10 & 1.58 \\
Loss of control over the quality of work produced & 2.44 & 1.52 \\
Organisation exposes itself to operational risk & 3.87 & 0.67 \\
It affects the continuity of skill supply and the retention of in-house knowledge & 3.86 & 0.70 \\
and expertise & & \\
Turning to an external provider causes disruption to the continuity of the & 3.55 & 0.76 \\
services & & \\
Average mean & $\mathbf{3 . 1 6}$ & \\
\hline
\end{tabular}

Source: (Field Survey, 2020)

Scale: $1.0-2.4=$ Disagree, $2.5-3.9=$ Agree

From Table 3, the strength of the responses reflecting in the average mean (3.16) suggests that these are challenges that hotels in Bono Ahafo Region faces for outsourcing their operations.

The results of outsourcing challenges in the hotels indicate that the respondents said that the hotels encounters challenges emanating from organisation exposes itself to operational risk with a mean score of $(M=3.87)$. The results convey a message to stakeholders of hospitality operators that not all outsourced staff could be trusted as some could condone and connive with criminals to cause mayhem. The study finding is in line with Lau and Zhang (2013) studied that found that outsourcing expose itself to operational risks such as loss of confidential information. The respondents further agreed that outsourcing affects the continuity of skill supply and the retention of in-house knowledge and expertise with a mean score of $(M=3.86)$. The finding implies that adoption of outsourcing may lead to denial of developments opportunities to your team. Thus, it could impede knowledge and skills of your staff members in your oganisation as a result of outsourcing. Additionally, respondents agreed $(\mathrm{M}=3.55)$ that turning to an external provider causes disruption to the continuity of the services. The findings support Beardwel and Claydon (2007) who point out that one of the draw backs is that it often eliminates direct communication between organisation and its clients. Other challenges were indicated as loss of control over the 
quality of work produced and decrease in customer satisfaction with a mean score of $(M=2.44)$ and $(M=2.10)$ respectively. The study results make a very important contribution to the field of hospitality industry by providing empirical evidence to the extent to which outsourcing activities significantly influenced customer satisfaction. The outcome of the study strengthens the work of Beardwell and Claydon (2007) who found that outsourcing may prevent organisation from building solid relationships with their customers and often leads to dissatisfaction on one or both sides.

\subsection{Regression Analysis Results}

Since the measures that were used to assess the primary constructs in the model were quantitative scales, regression analysis was used. Regression analyses are a set of techniques that can enable us to assess the ability of an independent variable(s) to predict the dependent variable(s). As part of the analysis, Regression Analysis was done. The results are as seen on Tables below:

Table 4: Regression Model Summary

\begin{tabular}{ccccc}
\hline Model & $\mathrm{R}$ & $\mathrm{R}$ Square & Adjusted R Square & Std. Error of the Estimate \\
\hline 1 & .689 & .475 & .465 & .475 \\
\hline
\end{tabular}

Dependent Variable: Organisational Performance

Predictors: (Constant), Employee innovation, Increase productivity, Competitive marketing, Focus on core areas and Better service to customers.

Table 5: ANOVA

\begin{tabular}{lccccc}
\hline & $\begin{array}{c}\text { Sum of } \\
\text { Squares }\end{array}$ & df & $\begin{array}{c}\text { Mean } \\
\text { Square }\end{array}$ & F & Sig. \\
\hline Regression & 2.083 & 1 & 2.083 & 1.696 & .001 \\
Residual & 113.733 & 38 & 2.993 & & \\
Total & 115.817 & 39 & & & \\
\hline
\end{tabular}

Dependent Variable: Organisational Performance

Table 6: Regression Coefficients

\begin{tabular}{|c|c|c|c|c|c|}
\hline \multirow[t]{2}{*}{ Model } & \multicolumn{2}{|c|}{$\begin{array}{l}\text { Unstandardised } \\
\text { Coefficients }\end{array}$} & \multirow{2}{*}{$\begin{array}{r}\text { Standardised } \\
\text { Coefficients }\end{array}$} & \multirow[t]{2}{*}{$\mathrm{t}$} & \multirow[t]{2}{*}{ Sig. } \\
\hline & B & Std. Error & & & \\
\hline (Constant) & 2.767 & .361 & .287 & 7.668 & .000 \\
\hline Employee innovation & 385 & .078 & .393 & 5.968 & .000 \\
\hline Increase productivity & 168 & .065 & 193 & 2.593 & .004 \\
\hline Competitive marketing & 284 & .065 & .324 & 4.383 & .000 \\
\hline Focus on core areas & .329 & .064 & .352 & 5.129 & .000 \\
\hline Customer service & .265 & .037 & .504 & 6.078 & .000 \\
\hline
\end{tabular}

\section{Dependent Variable: Organisational performance}

The results show a positive relationship between outsourcing and organisational performance. Coefficient of $\mathrm{R}$ $=0.689$; the $\mathrm{R}^{2}$ result was 0.475 .The result was significant at 0.001 . The implication is that outsource non-core functions will positively improve performance of the organisation. The results are consistent with the study by Alexander and Young (2016) and Okeke-Ezeanyanwu, (2017) that found that outsourcing increase productivity. The t-value was also significant hence the study concludes that outsourcing has a positive effect on organisational performance. 


\subsection{Conclusions}

The study was conducted to examine the effect of outsourcing on hotels performance in the Bono Ahafo Region of Ghana. On the effects of outsourcing on hotel performance, the study revealed that outsourcing strategies were found to help improve performance through employee innovation, increase productivity, profitability, maintains competitiveness in the market, allow hotels to focus on core areas and provide faster and offer quality service to customers. The regression results also, show a positive relationship between outsourcing and organisational performance. Coefficient of $\mathrm{R}=0.689$; the $\mathrm{R}^{2}$ result was 0.475 . The result was significant at 0.001 . The $\mathrm{t}$-value was also significant hence the study concludes that outsourcing has a positive effect on organisational performance.

However, outsourcing also impedes hotel performance. These include: hotels exposing themselves to operational risks; it also affects continuity of skill supply and the retention of in-house knowledge and expertise, and that turning to an external provider causes disruption in the continuity of services.

\subsection{Recommendations}

Based on the findings of the study, the researchers recommend the following:

1. There is the need for hotels to put in place risk control measures so that failures on the part of the outsourced agencies are curtailed.

2. Managers should consider other factors too while evaluating the cost and benefit of outsourcing, so as to ensure that the maximum benefit is achieved from the strategy in terms of reduced costs, risks and increase efficiency.

3. Policy makers in the hospitality industry should come up with policies that will spur the growth of the industry.

4. It is recommended that in-depth interviews should be conducted to solicit unstructured views from the respondents to get a broader understanding of effects of outsourcing on hotel operations.

\section{References}

Agyemang-Duah, P., Aikins,I., Asibey, O., and Broni,O., A. (2014). Evaluating the impact of outsourcing of non-core functions in the hotel industry: a case study of Anita, Noda and

Golden gate hotels European journal of business and innovation research, .2(3), 25-45.

Akinbola, G. (2012). Outsourcing impact on manufacturing firms' value: Evidence from Japan. Journal of Operations Management, 25(4), , 885-900.

from eujournal.org/index.php/esj/article/download/1259/1268.

Alexander, S. \& Young, R. (2016). Outsourcing HR and benefits. International journal of strategic management: Navigating the right course, 26(7), 15-23.

Barthelemy, J. (2010). Outsourcing and Firm-Level Performance. An International Journal, 8(4), 355-366.

Beardwell, J. \& Claydon, T. (2007). Human resource management: A contemporary approach (5th ed.). New York: Prentice Hall/Financial Times. 
Bolat, T., \& Yllmaz, Ö. (2018). The relationship between outsourcing and organizational performance: is it myth or reality for the hotel sector?. International Journal of Contemporary Hospitality Management, 21(1), 7-23.

Cox, N. (2014). Outsourcing buman resource function: Strategies for providing enhanced HR services at lower cost. New York: AMACOM.

Dibbern, B. \& Bustinza, O.F. (2016). Outsourcing, competitive capabilities and performance: an empirical study in service firms. International Journal of Production Economics, 126(2), 276-288.

Elmuti, D. (2014). The Perceived Impact of Outsourcing on Organizational Performance. Mid-American Journal of Business, 18 (2), 33-42.

Elmuti, D., \& Kathawala, Y. (2018). The effects of global outsourcing strategies on participants' attitudes and organizational effectiveness. International Journal of manpower 21(2), 112-128.

Eyaa, M. (2010). The Keys to successful Outsourcing, Procurement News”, March-2010, pp48.

Ghana Tourism Authority (2017). List of licensed hotels in Ghana, Accra: Ghana Tourism Authority

Ghana Tourism Authority (2018). List of hotels in Ghana, Accra: Ghana Tourism Authority

Hiamey, E., S. (2012). Challenges of hotel outsourcing in Ghana: A transaction cost perspective.

African Journal of Hospitality, Tourism and Leisure Vol. 2 (2) - (2012) ISSN: 2223-

$814 \mathrm{X}$

Isaksson, A. \& Lantz, B. (2015). Outsourcing strategies and their impact on financial performance in small manufacturing firms in Sweden. The International Journal of Business and Finance Research,9(4), 11-20.

Kattara, H. (2015). Career challenges for female managers in Egyptian hotels. International Journal of Contemporary Hospitality Management 17(3), 238-251.

Kiptum, R., M. (2014). Influence of outsourcing strategy on performance of three to five star hotels in Nairobi City County. A research project submitted in partial fulfillment of the requirement for the award of the master of business administration degree, school of business, university of Nairobi.

Lau, K.H. \& Zhang, J. (2013). Drivers and obstacles of outsourcing practices in China. International Journal of Physical Distribution \& Logistics Management, 36(10), 776 - 792.

Letica, M. (2016). The effect of outsourcing activities selection on the benefits of outsourcing. . Journal of contemporary management issues, 21(2), 77-97.

Lichtenthaler, M. (2011). Examining the premisses of Contracting out. Journal of Public productivity and management review 13(1), 28-32.

Muweesi, S. (2011). Consequences of outsourcing strategies on employee quality of work life, attitudes, and performance. Journal of Business Strategies, 27 (2), 123-128.

Okeke-Ezeanyanwu, J. A. (2017). Impact of Outsourcing on Organizational Productivity in Private and Public Sector Organizations in Anambra State. African Journal of Education, Science and Technology, 3(4), 112-116.

Olive, B. (2016). Outsourcing Growing, Despite Controversy". Power: 148(4),, 19-20. 
Stroh, A. \& Treehuboff, R. (2012). Effects of Outsourcing strategies on the organizational performance of fast foods industry in Lagos state. International journal of management reviews, 8(1), 49-70.

Suraju, R.F. \& Hamed, A.B. (2013). Outsourcing services as a strategic tool for organizational performance: An exploratory study of Nigerian food, beverage, and tobacco industry. Journal of Management Policies and Practices 1(1); June 2013 pp. 01-20.

Yeboah, A. (2013). The relationship between outsourcing and organizational performance. European Journal of Business and Management, 5(2), 2013. 